\title{
Solar Power Plant Grid Interactive and Building Integration Photovoltaic
}

\author{
Septianissa Azzahra ${ }^{1, *}$, Isworo Pujotomo ${ }^{1}$, and Muchamad Nur Qosim ${ }^{1}$ \\ ${ }^{1}$ Departement of Electrical Engineering, Sekolah Tinggi Teknik-PLN, Jakarta-Indonesia
}

\begin{abstract}
With the development of technology, the need for electricity is increasing. In terms of Indonesia's topology, the Solar Power Plant is most suitable for use in rural (remote) areas, known as the Solar Home System (SHS). This system is preferred because it is small in scale and uses a direct current (DC) system. This system can reduce costs because it does not use an inverter. But the weakness of this system is the difficulty of finding home electronic equipment such as TV, Radio / Tape and others that use DC, so the SHS system is not attractive to use. PLTS connected to PLN's electricity network, Interactive Grid, BIPV (Building Integration PV) is a hybrid application between the electricity network (PLN) and PLTS that are already widely used. Thus, PV-Genset Hybrids can reduce the inefficiency of operations and maintenance and reduce large initial investment costs
\end{abstract}

Keyword: grid; interactive; integration; photovoltaic.

\section{Introduction}

Although this time energy in Indonesia still depends on fossil energy. Even various technologies applied to the utilization of clean coal as dense medium cyclone, etc [1]. Indonesia needs to prepare the other energy as a replacement for fossil energy. Solar energy is one of the types of renewable energy sources or can be called potential renewable energy resources. Indonesia needs to prepare the other energy as a replacement for fossil energy [1]. Solar energy is one of the types of renewable energy sources or can be called renewable energy resources that are potential.

Solar Power Plants (PLTS) in Indonesia, most popularly used for rural electricity (remote), a system like this is popular as SHS (Solar Home System). SHS is generally a small scale system, using modules solar 50$100 \mathrm{Wp}$ (Watt Peak) and produce daily electricity of 150-300 Wh. Because of its small scale, DC (direct current) systems are preferred, to avoid losses and selfconsumption due to the use of an inverter.

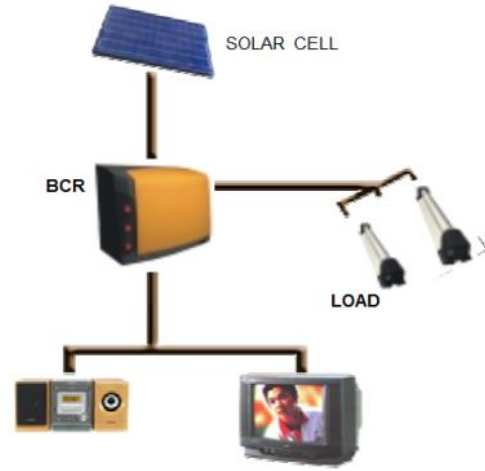

Fig. 1. SHS configuration
On the day of solar module receives the light of the sun and then converted into electrical power through the process of photovoltaic. Electricity produced by the module can be directly transmitted to the load or stored in the battery before used to burden: light, radio, etc. At night, where solar module does not produce electricity, a fully supplied burden by the battery. So when cloudy day where the solar modules produce electricity is lower compared to when the sun lit up [2,3].

PLTS system consists of three main components:

Solar Module; function alter the light of the sun into electricity flow clockwise (DC), the inverter can easily turn them into alternating current (AC) when needed.

Modular forms of the solar module provide ease of fulfilling the needs of electricity for a variety of the scale of need. The needs of small businesses can be fulfilled with one module or two modules and great necessity can be supplied by even thousands of solar modules stacked into one. One fruit of the solar module generally consists of 36 fruit of the solar cell.

Battery Charge Regulator; function manages the traffic power from the solar module to the battery and the burden. This electronic tool also has many functions that basically intended to protect the battery.

Battery / Accu; function stores the current electricity produced by solar module before used to move the burden.

The burden can be illumination or electronic equipment and other equipment that requires electricity. Solar Module will produce electricity in accordance with the level of the sun radiation that it receives. The level of radiation is different from one place to another, influenced by the layout of the location of the equator

\footnotetext{
*Corresponding author: septianissa@sttpln.ac.id
} 
(latitude), the height from the surface of the sea (altitude), the cloud, pollution, moisture, and temperature. However to facilitate, in Indonesia can be used guidelines 1 solar module capacity $50 \mathrm{Wp}$ can produce electricity as $150 \mathrm{Wh}$ (Watt hour or Watt hours per day).

To calculate how much power that will be needed to operate the electronic equipment (Wh), multiply Watt (AC or DC) equipment with ever (hours) the equipment will be used every day (cumulative). E.g. if 1 the fruit of the light 10 watts, want to lit in one day the cumulative during 15 hours, then will be needed electricity as much as 10 Watt $\times 1 \times 15$ hours $=150$ Wh (Watt Jam-Watt Hour).

\section{Hybrid PLTS - Genset}

Understanding Hybrid in this article is the use of 2 or more power plants with different energy sources, generally used for captive gensets, so obtained synergy that provides benefits economically and technically (=reliability system supply). Type load (Load profile) is an important keyword in the system according to brid. For each load profile that different, will be required system hybrid with a specific composition in order to achieve the optimum system. Therefore, system design and system sizing, have an important role to achieve the target made system hybrid.

As an example, a load profile that is relatively constant for 24 hours can be supplied efficiently and economically by gensets (with appropriate capacity), but load profile where electricity usage on the day far different compared with the night, will make use of gensets alone is not optimal. Below is a typical load profile for rural electric consumers [4].

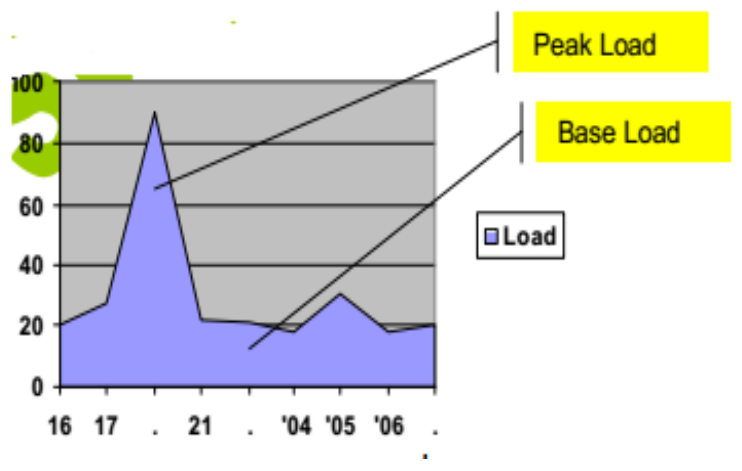

Fig. 2. Rural electric consumers

At the time of peak load, the use of gensets reach an optimum point, but at the base load, efficiency gensets very declined. On the load profile like this system hybrid very useful.

The purpose of the Hybrid PV of Gensets is combining the advantage of each power plant (in this gensets \& Power Generating System as well as to cover the weakness of each of the power plants to certain conditions so that the overall system can operate more economically and efficiently. Engineering requires a large initial investment but does not require the operation \& maintenance (O\&M) cost and cheaper for long-term, therefore ideal for energizing its base load, which are generally not too large. When used for energizing its peak load, the initial investment needed will be too large. On the other hand, initial investment gensets not big but O\&M cost high and expensive for the long term so that effective and efficient for energizing it load when the peak load, but not efficient in base load, because far below the optimum capacity.

\subsection{Configuration of Hybrid PV of Gensets}

System Hybrid PV of Gensets consists of four main components, as follows:

1. Gensets

Generate electricity AC, to system hybrid generally equipped with an automatic starter, so that the flame of the dead his gensets can be set automatically from the electronic controller.

2. Solar Power Generating System (PV)

Convert sunlight to DC power. Remember the hybrid system using solar module (Solar module/solar panel) insufficient amount many and all connected to both the series and parallel, then solar module with a capacity per panel $(>100 \mathrm{Wp} /$ panel) preferred, thereby reducing the need for a cable connection. Electricity produced by solar module, before entering into the distribution network is converted into electricity AC alternating current), therefore the output from the solar module sought with voltage $>12$ VDC (system voltage 48V 120 VDC common used). For this demand, BP Solar produces solar module $160 \mathrm{Wp}$. with system voltage $24 \mathrm{~V} \mathrm{DC}$, this connection easier to pursue the DC voltage is high. Serial connection/parallel between solar modules also comes with a diode-diode safety (Bypass Diode $\&$ Blocking Diode) to avoid short circuit, hot spot, and reverse current.

3. Electronic Controller/Bi directional Inverter

Often also referred to as a power conditioner. On the first and foremost function as: (a). Voltage glycemic load before in the power supply to the load, (b). Functioning as the inverter to convert the DC electricity produced by solar PV system to the AC power will supplied to load, (c). Functioning as the charger to charge the battery using the excess power from gensets, (d). Five function sets the charging the battery from the solar module, (e). Set up and manage which plants must work in accordance with the needs of the load, including switch off and switch on the gensets.

4. Battery

Function as buffer resources to overcome the time lag between it produces electricity by power (PV or gensets) with the time spent electricity by load. The size of the battery that is used is very depending on the size of the gensets, the size of the solar panel, and load pattern. The size of the battery that is too large for the efficiency of the operation but resulted in investment needs that too large, rather the size of the battery is too small can cause redundant accommodated from power plants and gensets too 
often goes on.[1, 4]. System hybrid by schematic served on the following diagram:

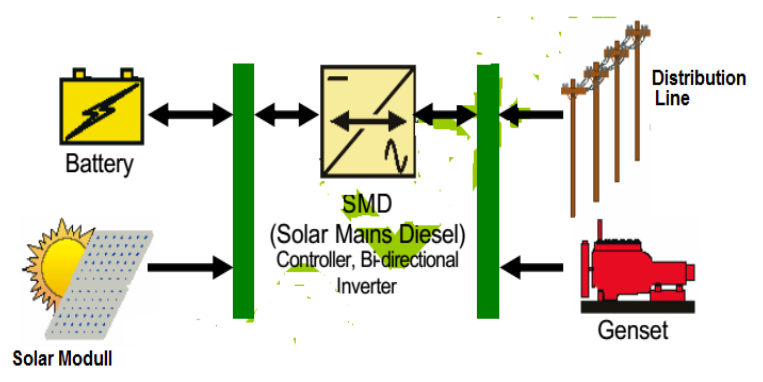

Fig. 3. Scheme of hybrid system

On certain hybrid system, the transition solar power generating system or gensets which operated done manually. This system is not recommended because it is very dependent on perfecting the operator in observing the behavior of the load. Hybrid System that better equipped with an automatic engine starter on the gensets where the death of his life gensets is set electronically. The development of technology system control for hybrid has very well at this end. When the load can be in power supply by solar power generating systems and battery, then SMD will convert the DC electricity from the solar power generating system or battery to AC power and in the power supply to the network. When the solar power generating systems and battery is not able to energize it load, gensets will turn to help energizing its electricity. Depending on the system sizing and the system design, this means basically base load will be supplied by solar power generating system (and battery), while peak load will be supplied by gensets. The battery will be in charge (charge) by two sources, i.e. solar power generating systems in the daytime, and gensets

From excessive redundant power (power) at gensets energizing its peak load, i.e. when peak load began to decline (and gensets still light). The above hybrid behavior can be set on the SMD, and set up his base is at the time of the determination of the system sizing and system design based on the load data profile.

\subsection{System Sizing \& Design}

System sizing is the process of determining the capacity (size) system based on the load profile that you want to in the power supply with attention to the ability of the output of each power plants. The capacity of the system hybrid solar power generating systems of Gensets that many used is $2.5 \mathrm{~kW}, 5 \mathrm{~kW}, 10 \mathrm{~kW}, 20 \mathrm{~kW}, 40 \mathrm{~kW}$, $60 \mathrm{~kW}, 80 \mathrm{~kW}$, and $100 \mathrm{~kW}$.

The composition of the portion of the solar power generating system and the portion of Gensets is determined by considering many aspects such as:

a) Fuel supply conditions (when the fuel supply is relatively difficult and genset portion tends to be scaled),

b) Fuel prices local when the local fuel price expensive then genset portion tends to be scaled, c) Load profile (see the discussion of the base load and peak load in relation to the power supply from the power plants), and

d) The ability of development cost (=investment; genset portion is too large cause O\&M high cost, but when the portion of a large power generating system and O\&M cost small but a major investment.

The composition of the commonly used is $20-40 \%$ solar power generating systems and $60-80 \%$ Gensets. The size of the battery will be calculated by considering the radiation of the sun (ESH, equivalent sun hour), load profile and the regulation of working hour gensets. The size of the battery is too small will cause gensets too often goes on, while when too large will result in high investment cost.

\section{Building Integration Photovoltaic}

Grid interactive is basically combining solar power generating system with electricity distribution network (PLN). Some people call it the term Hybrid solar power generating systems of PLN. The fundamental physical differences from this system with a hybrid system that has been described earlier are that the solar power generating system grid interactive does not use the battery so that this system far cheaper. Grid interactive generally used on the interconnection network.

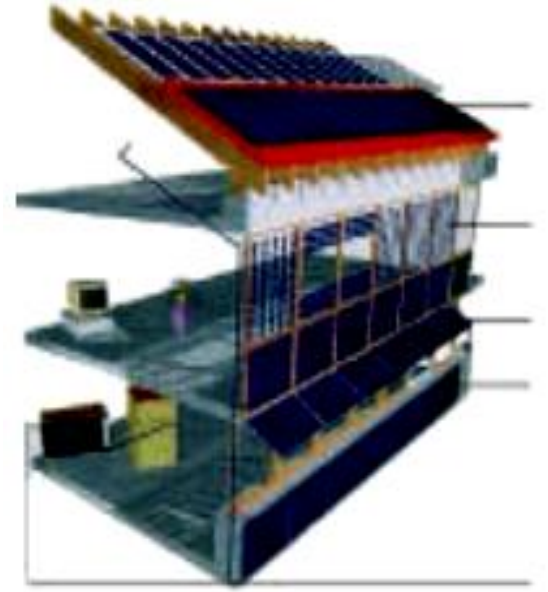

Roct Integaton ICU Apticaton Sunshade Systom Ficede Syssm

Fig. 4. Scheme of BIPV

Most interactive grid PLTS use is motivated by the desire to use environmentally friendly energy, and to overcome voltage instability (voltage sags, swells, spikes, and noise), and reduce the use of fuel in the generator interconnection system in rural areas. In a few developed countries, where awareness of the use of environmentally friendly energy is very large, the excess electricity generated by the Interactive PLTS-Grid that enters the network will be paid dearly by the utility company ( $\sim$ PLN), or given an adequate tax incentive, so the use of such systems is very soaring especially in Germany, Japan, and America in 2004-2006 and predicted to continue to increase. The Interactive Grid PLTS which is integrated with buildings is widely referred to as BIPV (Building Integration PV). 


\subsection{System Configuration}

Solar Power Generating System grid interactive only consists of solar module, controller and the inverter board. This equipment is connected to the electricity network PLN. By schematic presented below.

During the solar modules produce electricity (on the day) then the burden will supply by solar power generating systems. When the burden that must be supplied exceeds the capability of solar power generating system, or when the output of solar power generating system decreases (because the weather), or when the solar power generating system does not produce electricity (night), then the electricity from the network will go help. Because the system interactive work with the electricity network (grid) like this, then the system is called the solar power generating systemGrid Interactive.

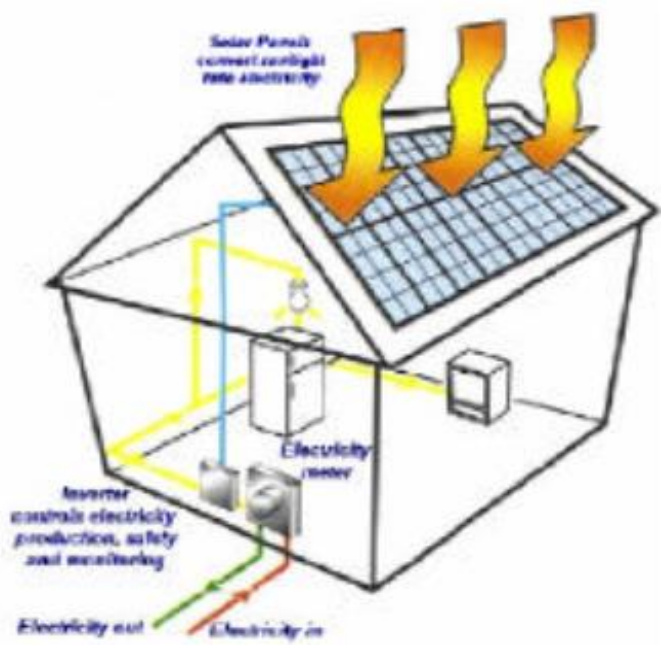

Fig. 5. PLTS grid interactive

As long as the solar module generates electricity (during the day) the load will be supplied by PLTS. If the load must be exceeded the ability of the PLTS, or if the output from PLTS is reduced (due to weather), or if the PLTS does not produce electricity (night days), then electricity from the network will come in to help. Because of the work system interactive with grid electricity like this, the system is called PLTS-Grid Interactive.

For security reasons, when the electricity from the network off, then the system will automatically also turn off the electrical supply of the solar power generating system, this is to prevent the "islanding". When the system is in place in a house/building, then when the electricity produced by the solar power generating system exceeds the load, the excess electricity will be entered into the network. The range of impedance, voltage, and frequency can be set to match the electrical behavior of the local network [5].

\section{Conclusion}

While Hybrid PV-Genset (both for stand-alone genset or generator sets interconnected), Hydro-PV Micro, and PV-Wind are hybrid applications widely used in rural areas, or for off-grid systems (isolated grids). The hybrid PLTS generator set is a combination of PLTS and Genset. Combination this is intended for: a). Reducing fuel consumption by reducing hours generator operation to only 3-4 hours per day, b). Reducing the cost of investment compared to when using all PLTS. Therefore this system is very suitable for places where the reliability of fuel supply is low.

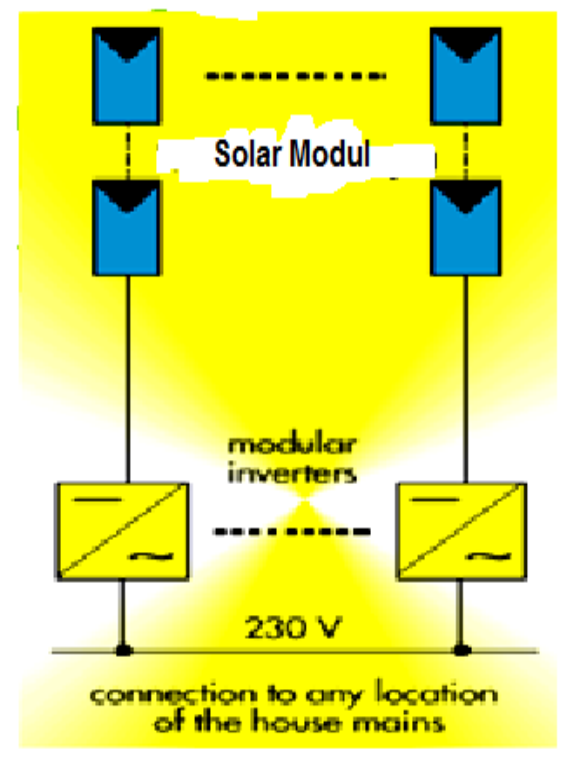

Fig. 6. PLTS grid interactive

Interactive Grid, BIPV (Building Integration PV) is a Hybrid application (= uses 2 or more energy generation systems different) between PLTS and Electrical networks. The interactive PLTS system is PLTS which is combined with an electricity network. When PLTS is sufficient, PLTS will supply all of the equipment, the electricity network will enter if the PLTS is unable to supply load. This system is suitable to be applied to participating regions

The factory where during the day the electrical quality of the network is very downhill. Because it doesn't need a battery, the interactive system is cheaper compared to hybrid systems.

\section{References}

1. I. Pujotomo, Clean Coal Technology Using Dens Medium Cyclone and Magnetite, American Scientific Publishers ASL 23(3), 2376-2378 (2017)

2. P. Eiffert, Building-Integrated Photovoltaic Designs for Commercial and Institutional Structures: A Source Book for Architect, 60-61 (2000)

3. P. Eiffert, G. Kiss, Building-Integrated Photovoltaic Designs for Commercial and Institutional Structures: A Source Book for Architect, ISBN 9781-4289-1804-7, 59 (2000)

4. A. Henemann, BIPV: Built- in Solar Energy". Renewable Energy Focus, Science Direct 9(6), 14, 16-19 (2008)

5. S. Strong, Building Integrated Photovoltaics (BIPV), Whole Building Design Guide (2010) 